\title{
Colorimetric immunosensor for determination of prostate specific antigen using surface plasmon resonance band of colloidal triangular shape gold nanoparticles
}

\author{
Pari Karami a , Hosein Khoshsafar a , Mohammad Johari-Ahar ${ }^{\text {b,c }}$, Fabiana Arduini ${ }^{\mathrm{d}}$, \\ Abbas Afkhami ${ }^{\mathrm{e}}$, Hasan Bagheri ${ }^{\mathrm{f}}{ }{ }$, \\ ${ }^{a}$ Research and Development Department, Farin Behbood Tashkhis LTD, Tehran, Iran \\ b Department of Medicinal Chemistry, School of Pharmacy, Ardabil University of Medical Sciences, Ardabil, Iran \\ c Biosensor Research Center (BRC), Ardabil University of Medical Sciences, Ardabil, Iran \\ d Department of Chemical Science and Technologies, University of Rome Tor Vergata, Via della Ricerca Scientifica, 00133 Rome, Italy \\ e Faculty of Chemistry, Bu-Ali Sina University, Hamedan, Iran \\ ${ }^{\mathrm{f}}$ Chemical Injuries Research Center, Systems Biology and Poisonings Institute, Baqiyatallah University of Medical Sciences, Tehran, Iran
}

\section{A R T I C L E I N F O}

\section{Article history:}

Received 19 March 2019

Received in revised form 12 May 2019

Accepted 27 May 2019

Available online 29 May 2019

\section{Keywords:}

Colorimetric immunosensor

Sandwich assay

Surface plasmon resonance

Total prostate specific antigen

Magnetic nanoparticles

\begin{abstract}
A B S T R A C T
In this work, we demonstrated the development of a colorimetric immunosensor using surface plasmon resonance band of gold nanoparticles for the detection of prostate specific antigen (PSA). To develop this biosensing tool, triangular gold nanoparticles (AuNPs) were synthesized using Tween-20 as a nonionic surfactant and then, conjugated with PSA capture antibody ( $\mathrm{Ab}_{1}$-AuNPs). When exposed to $A b_{1}$-AuNPs, PSA antigens were found to be successfully captured by nanosystem (PSA)-Ab ${ }_{1}$-AuNPs. Next, (PSA)-Ab $\mathrm{b}_{1}$-AuNPs were incubated with second PSA antibody (2)-decorated magnetite $\left(\mathrm{Fe}_{3} \mathrm{O}_{4}-\mathrm{Ab}_{2}\right)$ and separated by an external magnetic force to leave $\mathrm{Ab}_{1}$ AuNPs in the supernatant solution to be directly analyzed using UV-Vis spectroscopy. It was found that the absorption intensity was directly proportional to the PSA concentration. As a result, the linear range for PSA detection was found to be $0.01-20 \mathrm{ng} \mathrm{mL}^{-1}$ with a detection limit of $0.009 \mathrm{ng} \mathrm{mL}^{-1}$. Because of significant stability of the prepared $\mathrm{Ab}_{1}$-AuNPs and excellent selectivity to the PSA antigen, this simple and sensitive sensing system is proposed to be potentially effective in the fast and real-time analysis of clinical samples from prostate cancer patients. We believe that the simple platform of this immunosensor to be useful in the development of future point-of-care sensing tools, working on the quantification of biomarkers in a drop of blood.
\end{abstract}

(c) 2019 Elsevier B.V. All rights reserved.

\section{Introduction}

Prostate specific antigen (PSA) is a glycoprotein that generally exists in healthy adult males below $4 \mathrm{ng} \mathrm{mL}^{-1}$, but clinically, abnormal levels of PSA is an important serum biomarker for early and differential diagnosis of benign prostatic hyperplasia (BPH) and prostate cancer and evaluation of patient's response to chemotherapy $[1,2]$. In this way, it is really important to establish new sensing methods to approach simple, rapid and accurate detection of such biomarker for early-stage diagnosis of prostate cancer to avoid unpredictable metastasis.

Till now, a variety of assays such as chromatography [3], mass spectroscopy [4], fluorescence spectroscopy [5], nuclear magnetic resonance spectroscopy [6], white light reflectance spectroscopy [7], capillary

\footnotetext{
* Corresponding author.

E-mail address: h.bagheri@bmsu.ac.ir (H. Bagheri).
}

electrophoresis [8], chemiluminescence [9], enzyme-linked immunosorbent assays (ELISA) [10], electrochemiluminescence [11,12], radioimmunoassay [13], time-resolved immunofluorometric assay [14], surface plasmon fluorescence immunoassay [15], bioluminescent immunoassay [16], electrochemical [17], surface-enhanced Raman scattering [18], and microcantilever method [19] have been developed for the determination of PSA. These methods unfortunately encounter with challenges for clinical applications, necessitating skilled personnel working with expensive, time-consuming and complex technology [20-22].

In attempt to removing such limitations, sandwich-type colorimetric immunoassays based on lateral surface plasmon resonance as a noninvasive strategy have represented capacity of simplicity, low-cost translation, and tailoring to point-of-care applications.

With introduction of nanomedicine, a convergence of nanoscience and medicine, nanomaterials have attracted great attention in all fields 
of science [23-28]. Of various nanoparticles exploited in the era of bioanalytical sciences, gold nanoparticles with different sizes and shapes have been successfully used as a signaling probe for sensitive analysis of cancer biomarkers [29,30]. Due to having unique and tunable surface plasmon resonance (SPR) properties, gold nanoparticles (AuNPs) have been the subject of intensive research on UV-Vis extinction bands. When the frequency of an incident photon with the conduction electrons of AuNPs is in proper resonance, SPR as wavelengthselective absorption with extremely large molar extinction coefficients can be induced [31].

Due to having a narrow plasmon peak, stability in the complex system of biological samples, and greater molar extinction coefficient, nonspherical gold nanoparticles especially triangular AuNPs are prone to improve sensitivity of detection and to lower the limit of detection. Triangular AuNPs significantly exhibit excellent stability at high salt concentrations $\left(0.1 \mathrm{~mol} \mathrm{~L}^{-1}\right)$, and are laborious to separate [31]. To reach efficient separation, application of magnetic nanoparticles in connection with gold nanoparticles leads to approaching lower detection limits and fast responsive biosensors [32]. In the field of bio-separation, Magnetic nanoparticles are defined as core nanomaterials and magnetite $\left(\mathrm{Fe}_{3} \mathrm{O}_{4}\right)$ nanoparticles are generally used to magnetically isolate proteins, DNA, viruses and even whole mammalian cells [33].

In this work, we demonstrate the development of a colorimetric sandwich-type immunosensor for detection of PSA using lateral surface plasmon resonance of triangular AuNPs and magnetic force separation of $\mathrm{Fe}_{3} \mathrm{O}_{4}$ NPs decorated with PSA-specific antibodies ( $\mathrm{Ab}_{1}$-AuNPs and $\mathrm{Fe}_{3} \mathrm{O}_{4}-\mathrm{Ab}_{2}$ ).

\section{Materials and methods}

\subsection{Chemicals}

Tween-20, $\mathrm{NaOH}, \mathrm{HCl}, \mathrm{K}_{2} \mathrm{HPO}_{4}$, and $\mathrm{KH}_{2} \mathrm{PO}_{4}$ were purchased from Merck (Darmstadt, Germany). 3-(Trimethoxysilyl)-propylamine (APTS), acetic acid, hydrogen tetrachloroaurate $\left(\mathrm{HAuCl}_{4} .3 \mathrm{H}_{2} \mathrm{O}, 99.5 \%\right)$, magnetite $\left(\mathrm{Fe}_{3} \mathrm{O}_{4}\right)$ and hexane were obtained from Sigma-Aldrich company. (St. Louis, Missouri, United States). Monoclonal anti-PSA antibodies $\left(A b_{1}\right.$ (1H12, epitope 4$)$ and $A b_{2}$ (5A6, epitope 6$)$ ) were obtained from HyTest (Turku, Finland). PSA ELISA kit was purchased from (R\&D Systems, Minneapolis, MN, USA). All solutions were prepared with deionized water with a specific resistance $18.2 \mathrm{M} \Omega \times \mathrm{cm}$ (million ohms) at $25^{\circ} \mathrm{C}$. (Merck Millipore, Darmstadt, Germany). All of the glassware was cleaned by aqua regia ( $\mathrm{HCl}: \mathrm{HNO}_{3}$ in a 3: 1 ratio by volume) and rinsed with water prior to the experiments.

\subsection{Apparatus}

UV-Vis spectroscopy was performed on a Perkin-Elmer Lambda 25 spectrophotometer with the use of semi-micro spectrophotometric cuvettes. Transmission electron microscopy (TEM) images were recorded using a Philips CM10 TEM (USA) at an accelerating voltage of $80 \mathrm{kV}$. The size distributions of the nanoparticles were obtained using Nanotrac Wave $^{\mathrm{TM}}$ (Microtrac, San Diego, CA, USA). The size of nanoparticles was calculated by fitting the data to a polydispersed model using the Dynamics software version 5.26 (Microtrac, San Diego, CA, USA).

\subsection{Preparation of $A b_{1}$-AuNPs}

The AuNPs were prepared based on our previously reported method [31]. Briefly, $4 \mathrm{~mL}$ of Tween-20 solution $20 \%(\mathrm{v} / \mathrm{v})$ in PBS ( $\mathrm{pH}=7.0$ ) was added to $1 \mathrm{~mL}$ of $\mathrm{HAuCl}_{4}\left(10 \mathrm{mmol} \mathrm{L}^{-1}\right)$. Carboxylic functional groups of tween-20 were activated using a solution containing EDC $\left(20 \mathrm{mg} \mathrm{mL}^{-1}\right)$ and NHS $\left(10 \mathrm{mg} \mathrm{mL}^{-1}\right)$ in borate buffer $(\mathrm{pH}=9)$ under shaking $(60 \mathrm{rpm})$ at room temperature and dark for $30 \mathrm{~min}$.

To covalently attach AuNPs with $A b_{1}$, the activated nanoparticles were incubated with $\mathrm{Ab}_{1}\left(50 \mu \mathrm{g} \mathrm{mL}^{-1}\right)$ solution at $8{ }^{\circ} \mathrm{C}$ and dark under shaking ( $60 \mathrm{rpm}$ ) for $24 \mathrm{~h}$. after washing with Tween-20 solution 20\% $(\mathrm{v} / \mathrm{v})$ to remove unconjugated $A b_{1}$, the antibody-conjugated Au NPs $\left(A b_{1}\right.$-AuNPs) were centrifuged at $4000 \times g$ for $5 \mathrm{~min}$, and finally the precipitation was finally dispersed and stored in a solution containing $0.1 \%$ sodium azide at $4{ }^{\circ} \mathrm{C}$ for next applications.

\subsection{Preparation of $\mathrm{Ab}_{2}-\mathrm{Fe}_{3} \mathrm{O}_{4}$}

The $\mathrm{Fe}_{3} \mathrm{O}_{4}$ NPs were prepared by the silanization method [34]. Initially, in a glass container under ambient conditions, 0.5\% (v/v) APTS solution was added to a dispersion of $\mathrm{Fe}_{3} \mathrm{O}_{4}$ solution $\left(0.5 \mathrm{mg} \mathrm{mL}^{-1}\right)$ in hexane containing $0.01 \%(\mathrm{v} / \mathrm{v})$ acetic acid. The mixture was shaken for $72 \mathrm{~h}$ during which the nanoparticles were precipitated. The APTSmodified $\mathrm{Fe}_{3} \mathrm{O}_{4}$ NPs (APTS- $\mathrm{Fe}_{3} \mathrm{O}_{4}$ ) were separated using an external magnet and then washed with hexane three times to remove all unreacted silanes. The product was finally redispersed in deionized (DI) water.

Carboxylic functional groups of APTS- $\mathrm{Fe}_{3} \mathrm{O}_{4}$ were activated using a solution containing EDC $\left(20 \mathrm{mg} \mathrm{mL}^{-1}\right)$ and NHS $\left(10 \mathrm{mg} \mathrm{mL}^{-1}\right)$ in borate buffer ( $\mathrm{pH} 9$ ) under shaking (60 rpm) at room temperature and dark for $30 \mathrm{~min}$.

To covalently attach APTS-Fe $\mathrm{O}_{4}\left(0.2 \mathrm{mg} \mathrm{mL}^{-1}\right) \mathrm{NPs}$ with $\mathrm{Ab}_{2}$, the activated NPs were incubated with $\mathrm{Ab}_{2}\left(50 \mu \mathrm{g} \mathrm{mL}^{-1}\right)$ solution at $8{ }^{\circ} \mathrm{C}$ and dark under shaking (60 rpm) for $24 \mathrm{~h}$. The prepared $\mathrm{Fe}_{3} \mathrm{O}_{4}-\mathrm{Ab}_{2} \mathrm{NPs}$ were separated using an external magnet and then washed with DI water three times to remove all unconjugated $\mathrm{Ab}_{2}$ molecules. The final product was dispersed in PBS buffer $\left(10 \mathrm{mmol} \mathrm{L}^{-1}\right)$ containing $0.1 \% \mathrm{so}$ dium azide and stored at $4{ }^{\circ} \mathrm{C}$ for next applications.

\subsection{Determination of PSA}

In order to analyze PSA, $1.5 \mathrm{~mL}$ of standard solutions $\left(1 \mathrm{mmol} \mathrm{L}{ }^{-1}\right.$ PBS, $\mathrm{pH}=7.4$ ) containing distinctive content of PSA were incubated with $50 \mu \mathrm{L}$ of $\mathrm{Ab}_{1}$-AuNPs $\left(0.1 \mathrm{mg} \mathrm{mL}^{-1}\right)$. The shaker incubator with a rotation speed of $200 \mathrm{rpm}$ at $25^{\circ} \mathrm{C}$ for 70 min was used for the completion of antigen-antibody reactions.

Afterward, $50 \mu \mathrm{L}$ of $\mathrm{Fe} 3 \mathrm{O} 4-\mathrm{Ab}_{2}$ suspension was added and incubated with a rotation speed of $200 \mathrm{rpm}$ on a shaker at $25^{\circ} \mathrm{C}$ for $60 \mathrm{~min}$. After magnetic separation (MS) of the formed immune-complexes (Fe304$A b_{2}$-(PSA)-Ab $b_{1}$-AuNPs), a portion of the supernatant was directly transferred into semi-micro spectrophotometer cuvettes for measurement of absorption.

The absorptions were recorded at $525 \mathrm{~nm}$ as the $\lambda_{\max }$ of Au NPs SPR. Final absorption was calculated by subtracting the absorption of the corresponding blank samples. In order to confirm the reproducibility, each immunoassay had to be completed in triplicate. Scheme 1 illustrates the principle of the immunosensor development.

\subsection{Serum sample analysis}

The potential basic and clinical applicability of the immunosensor was tested for the determination PSA in blood serum samples obtained from healthy and patient volunteers. The results of the immunosensor were compared with those of ELISA method. The samples were diluted 2-fold by $1 \mathrm{mmol} \mathrm{L}^{-1} \mathrm{PBS}$ ( $\mathrm{pH}$ 7.0) before analysis.

\section{Results and discussion}

\subsection{Characteristics of immunosensor}

\subsubsection{UV-Vis spectroscopy analysis}

The engineered immunosensor was first characterized by UV-Vis spectroscopy. As shown in Fig. 1, Panel A, the absorption of bare $\mathrm{Fe} 3 \mathrm{O} 4$ (APTS-Fe3O4), Fe3O4- $\mathrm{Ab}_{2}$ and $\mathrm{Fe} 3 \mathrm{O} 4-\mathrm{Ab}_{2}-(\mathrm{PSA})$ nanoparticles were the measurement in the range of $200-900 \mathrm{~nm}$. After immobilization of $\mathrm{Ab}_{2}$ on $\mathrm{Fe} 3 \mathrm{O} 4$, an obvious absorption peak appeared at $300 \mathrm{~nm}$ 


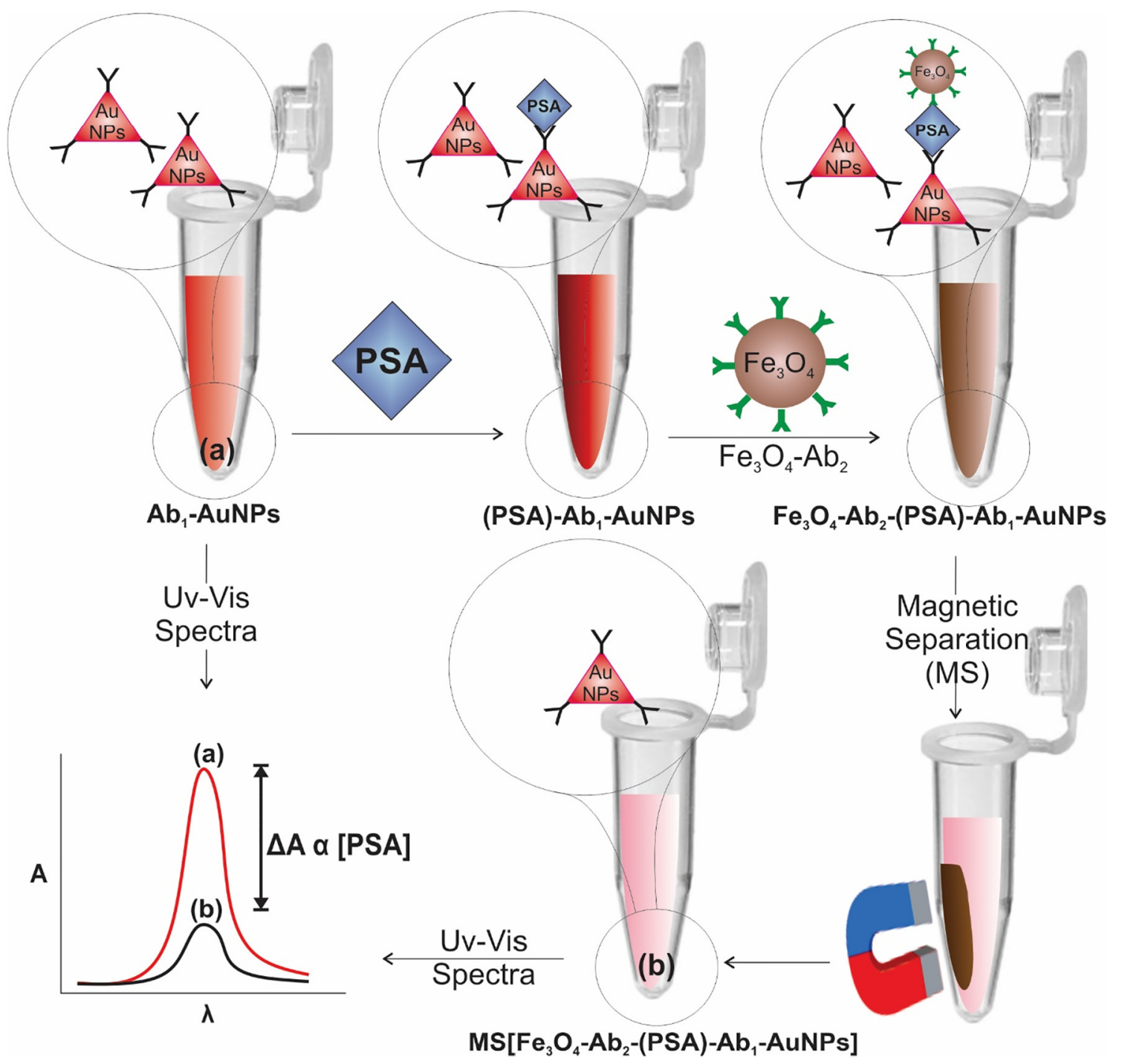

Scheme 1. The performance of the immunosensor.

(curve $\mathrm{b}$ ), which can be an indicator of $\mathrm{Ab}_{2}$ immobilization on the surface of Fe3O4 NPs. After the interaction of PSA and Fe3O4-Ab (curve $^{2}$ c), the slight bathochromic shift in plasmon band position confirms the formation of immuno-complex.

As shown in Fig. 1, Panel B, the bare AuNPs exhibit an absorption peak at $515 \mathrm{~nm}$, ascribing to SPR pf AU NPs (curve j). After being coated with antibodies ( $A b_{1}$-AuNPs) (curve $\mathrm{k}$ ), an obvious absorption peak appeared at $300 \mathrm{~nm}$, indicating the successful immobilization of $A b_{1}$ on the surface of AuNPs and red-shifting of SPR peak from 515 to $525 \mathrm{~nm}$ due to the increase in the hydrodynamic diameter of AuNPs. Moreover, the results clearly indicated immune-complexation of PSA and $\mathrm{Ab}_{1^{-}}$ AuNPs (Fig. 1, Panel C, curve e) resulted in an obvious absorption peak at $620 \mathrm{~nm}$, which can be due to the aggregation of $A b_{1}$-AuNPs. After interaction of $\mathrm{Fe} 3 \mathrm{O} 4-\mathrm{Ab}_{2}$ and (PSA)-Ab ${ }_{1}$-AuNPs, the SPR peak shifted from $620 \mathrm{~nm}$ to $725 \mathrm{~nm}$, indicating to the significant increase in the diameter of the formed nano-complex $\left(\mathrm{Ab}_{1}\right.$-AuNPs -Fe3O4-Ab $\left.{ }_{2}\right)$ (Fig. 1 , Panel C, curve f). When magnetic separation was applied on Fe304$A b_{2}$-(PSA)-Ab $b_{1}$-AuNPs, the UV-Vis absorption of $A b_{1}$-AuNPs decreased significantly (Fig. 1, Panel C, curve g) because the formation of complexation between (PSA)-Ab ${ }_{1}$-AuNPs and Fe3O4- $\mathrm{Ab}_{2}$ led to the dropping of $A b_{1}$-AuNPs concentration in the supernatant. Fig. 1 , Panel $C$, curve $h$ indicates that the absorption peak of $\mathrm{Ab}_{1}$-AuNPs is not affected by Fe3O4$\mathrm{Ab}_{2} \mathrm{NPs}$.

\subsubsection{TEM and DLS analysis}

The size and shape of gold nanoparticles strongly influence their chemical and other properties. The triangular shaped nanoparticles show attractive optical properties in comparison to spherical one $[35,36]$. So, in the present work, triangular-shaped gold nanoparticles were used instead of conventional citrate-capped gold nanoparticles for constructing colorimetric immunoassay. The prepared NPs were characterized by TEM and DLS, as shown in Fig. 1. As expected, the Fe3O4- $\mathrm{Ab}_{2}$ NPs were spherical with a mean diameter of $34.5 \mathrm{~nm}$ (Panels $D_{I}$ and $D_{I I}$. As shown in Fig. 1, Panels $E_{I}$ and $E_{I I}, A b_{1}$-AuNPs had a truncated triangular shape with an average edge length of $28.4 \mathrm{~nm}$. The TEM and DLS images of the $\mathrm{Fe}_{3} \mathrm{O}_{4}-\mathrm{Ab}_{2}$ and $\mathrm{Ab}_{1}$-AuNPs aggregation in the presence of PSA antigen resulted in the mean diameter of $88.2 \mathrm{~nm}$ (Fig. 1, Panels $F_{I}$ and $F_{I I}$, representing that Fe3O4-Ab $b_{2}$ and $A b_{1}$-AuNPs have the capability of forming a sandwich structure $\mathrm{Fe} 3 \mathrm{O} 4-\mathrm{Ab}_{2}$-(PSA)$\mathrm{Ab}_{1}$-AuNPs.

\subsection{Optimization of the experimental parameters}

\subsubsection{Interaction of PSA with $A b_{1}$-AuNPs}

To find the optimum incubation time for completion of complex formation between PSA and $\mathrm{Ab}_{1}$-AuNPs, UV-Vis spectra were recorded at different time points. The results, as shown in Fig. 2, Panel $A_{I}$, indicated 

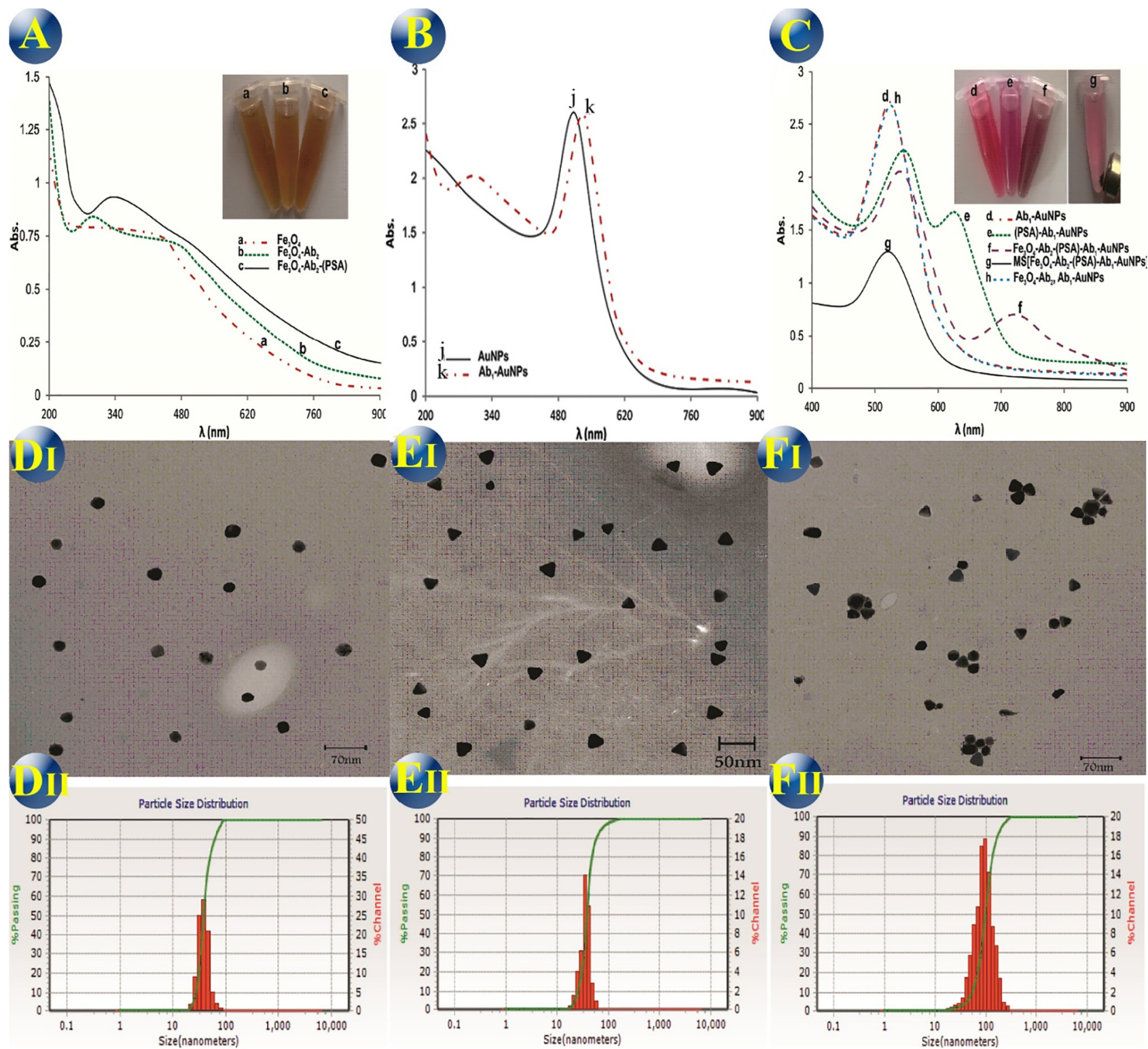

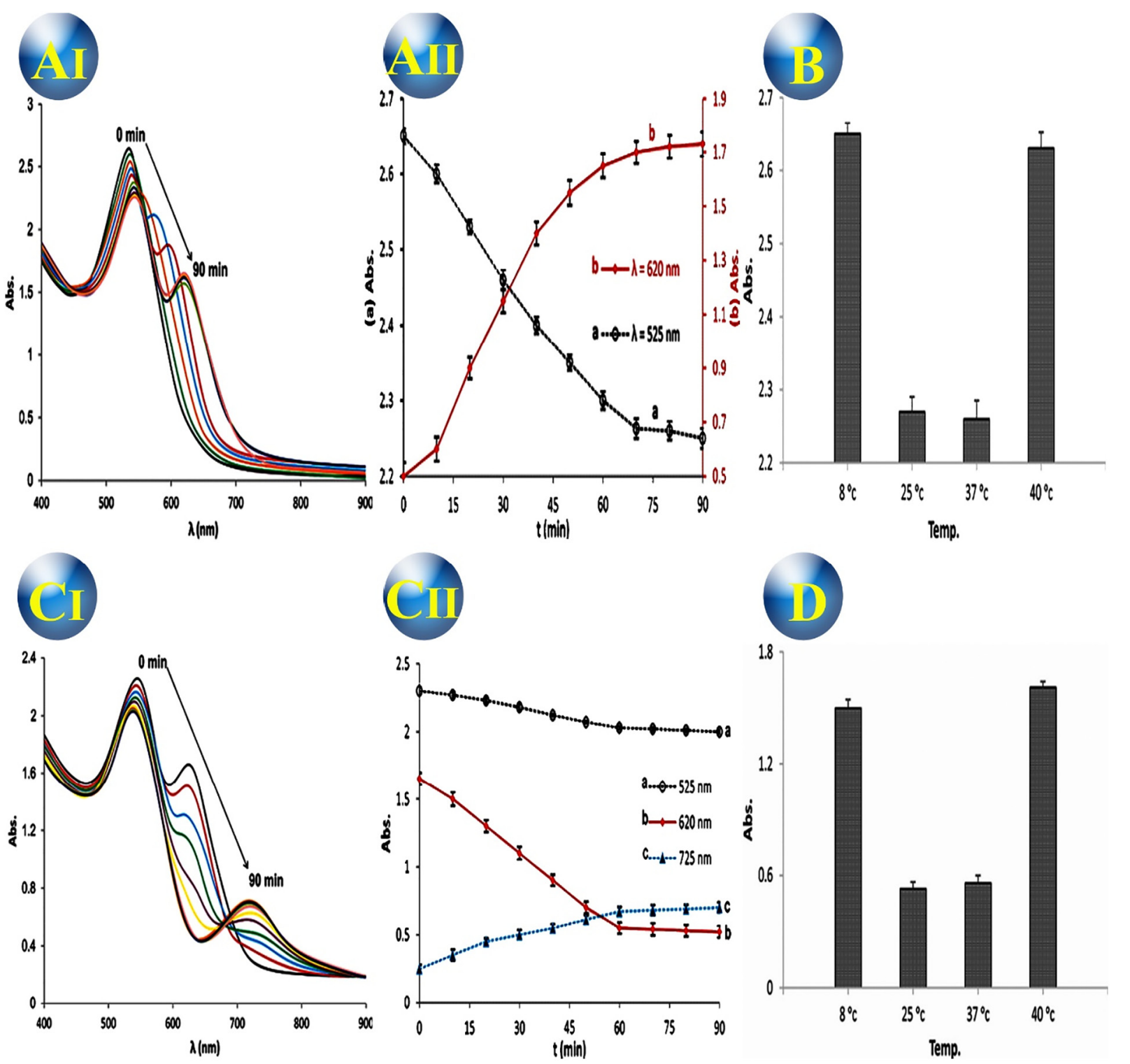

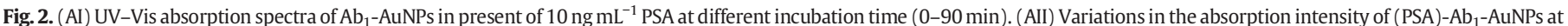

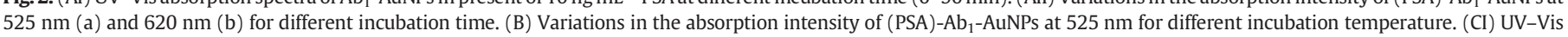

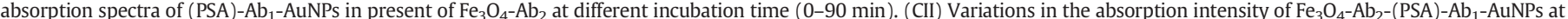

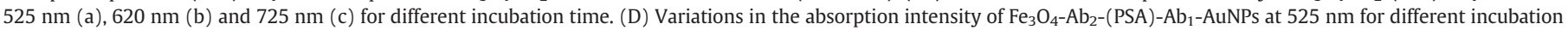
temperature.

resulted from formed layers of tween-20 molecules led to the steric stabilization of the prepared Au NPs and prevent to aggregation of nanoparticles in high ionic strength solutions.

Moreover, the $\mathrm{Ab}_{1}$-AuNPs, shown in Fig. S1, Panel A (see Supplementary Material), represented remarkable stability over a wide range of $\mathrm{pH}$ values (5-9). Fig. S1, Panel B (see Supplementary Material) shows the result of the study on absorption of (PSA)-Ab $\mathrm{b}_{1}-\mathrm{AuNPs}$ at $\mathrm{pH}$ values ranging from 5 to 9 . With the increase of $\mathrm{pH}$, the SPR peaks shifted to the red region, and the size of Au NPs increased in contrast

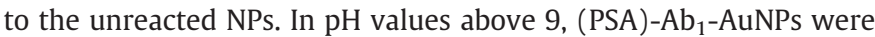
completely aggregated (Fig. S1, Panel D, curve a, see Supplementary Material) (Fig. S1, Panel D, curve b, see Supplementary Material). Fig. S1, Panel C (see Supplementary Material) shows the absorption of $A b_{1}$-AuNPs after applying an external magnetic field for separation of $\mathrm{Fe}_{3} \mathrm{O}_{4}-\mathrm{Ab}_{2}$-(PSA)- $\mathrm{Ab}_{1}$-AuNPs at the measured $\mathrm{pH}$ values. The tighter the interaction of $\mathrm{Ab}_{1}$-AuNPs with $\mathrm{Fe}_{3} \mathrm{O}_{4}-\mathrm{Ab}_{2}$ via PSA molecules, the lower the $A b_{1}$-AuNPs in the supernatant and the shorter absorption peak. The greater absorption peaks were observed at $\mathrm{pH}$ of 5,6 and 9, which can be due to the dissociation of $\mathrm{Fe}_{3} \mathrm{O}_{4}-\mathrm{Ab}_{2}-(\mathrm{PSA})-\mathrm{Ab}_{1}$-AuNPs complex and release of $\mathrm{Ab}_{1}$-AuNPs. However, based on absorption data, it can be concluded that the most stable complexes are formed at physiological $\mathrm{pH}$.

In addition, the effect of $\mathrm{pH}$ on the sensitivity of the immunosensor showed that maximum sensitivity in the performance of the immunosensor is observed in physiological pH values (Fig. S2, see Supplementary Material).

\subsection{Analytical features}

\subsubsection{Determination of PSA}

Under the optimized conditions, UV-Vis absorption spectra of the $\mathrm{Ab}_{1}$-AuNPs, after incubation with $\mathrm{Fe}_{3} \mathrm{O}_{4}-\mathrm{Ab}_{2}$ in the presence of standard concentrations of PSA were recorded, and the results showed that after applying external magnetic field to isolate $\mathrm{Fe}_{3} \mathrm{O}_{4}-\mathrm{Ab}_{2-}(\mathrm{PSA})-\mathrm{Ab}_{1}$ AuNPs, the intensity of plasmon absorption peak of $A b_{1}$-AuNPs is inversely proportional to the concentration of PSA (Fig. 3, Panel A). For 

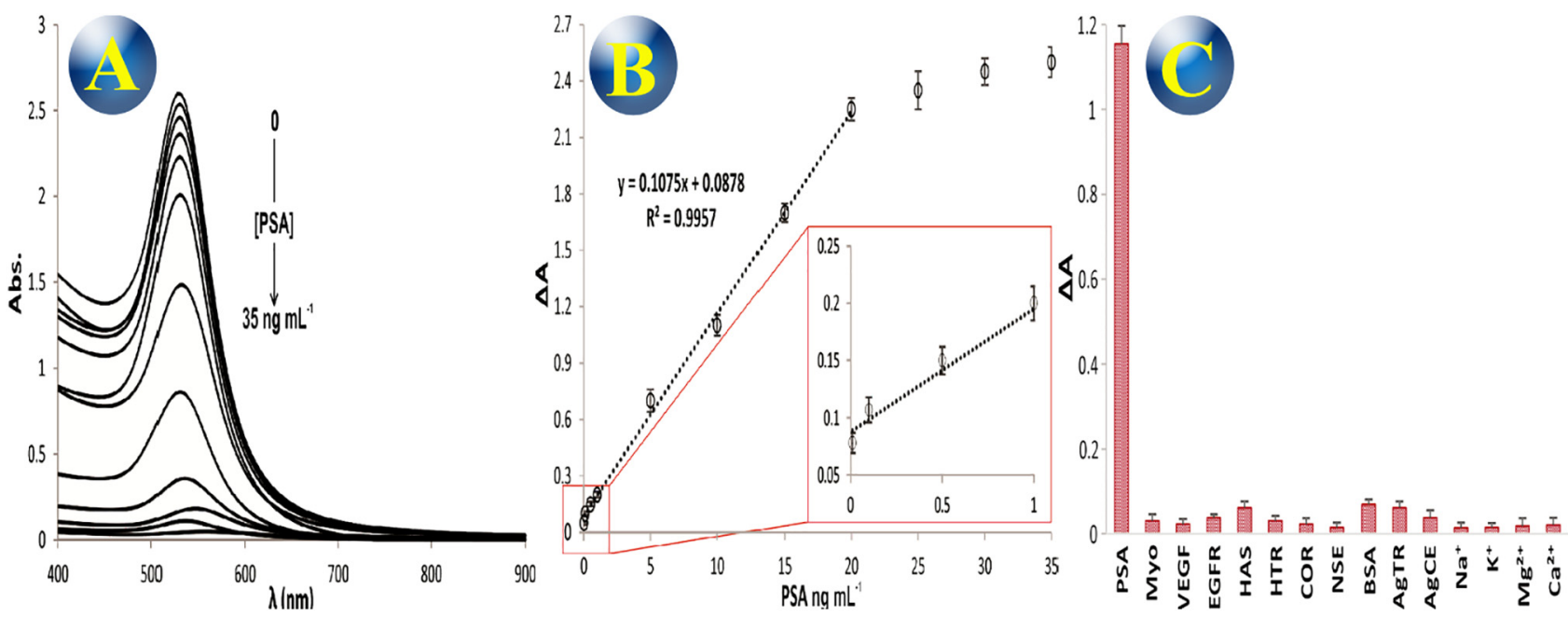

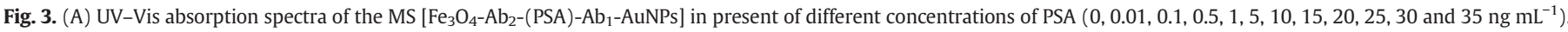

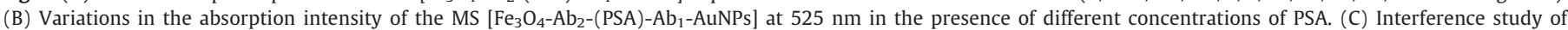

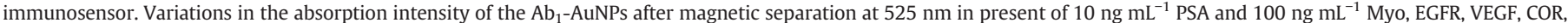
NSE, HTR, HAS, BSA, AgTR and AgCE and $0.05 \mathrm{~mol} \mathrm{~L}^{-1} \mathrm{Na}, \mathrm{K}, \mathrm{Ca}^{2}$ and $\mathrm{Mg}^{2}$.

this analysis, linear dynamic range (LDR) and limit of detection (LOD) were found to be $0.01-20 \mathrm{ng} \mathrm{mL}^{-1}$ and $0.009 \mathrm{ng} \mathrm{mL}^{-1}$ with an equation of $\Delta \mathrm{A}=0.1075 \pm 0.0032$ [PSA] $\left(\mathrm{ng} \mathrm{mL}^{-1}\right) \quad 0.0878 \pm 0.0064$ (Fig. 3, Panel $B)$. Table 1 represents the main characteristics of the sensing tools and comparison of the immunosensor with this PSA detection methods. This comparison confirms that the sensing tool in this work as a simple and rapid colorimetric method can rival in the sensitivity and limit of detection.

\subsubsection{Interference study}

For the assessment of immunosensor specificity, assortment of biomarkers including PSA, epidermal growth factor receptor (EGFR), vascular endothelial growth factor (VEGF), cortisol (COR), neuron-specific enolase (NSE), human thrombin (HTR), human albumin serum (HAS), bovine serum albumin (BSA), thrombin antigen (AgTR), myoglobin (Myo),carcinoembryonic antigen ( $\mathrm{AgCE}$ ) and sodium (Na), potassium $(\mathrm{K})$, calcium $\left(\mathrm{Ca}^{2}\right)$, magnesium $\left(\mathrm{Mg}^{2}\right)$ were investigated for interfering signals. As shown in Fig. 3, Panel C, the maximum change in absorption value was obtained from $10 \mathrm{ng} \mathrm{mL}^{-1}$ of PSA, while negligible changes in the absorption intensity were observed in the presence of at least 10- fold higher concentrations of the other tested proteins. The result is indicative of high selectivity of the method, which can be attributed to the high specificity of the antibodies modified nanoparticles toward PSA.

\subsubsection{Accuracy, repeatability, stability and reversibility of immunosensor}

To demonstrate the viability of the immunosensor in clinical assays, content of PSA in serum samples of healthy donor and prostate cancer patient were analyzed and revalidated by standard ELISA technique. It was observed that there was no significant difference between the results from the immunosensor and ELISA results $(p<0.05)$, confirming the satisfactory accuracy and precision of the immunosensor. In comparison with some parameters, immunosensor represented advantages over ELISA method (Table 2). Moreover, the presence of proteins other than PSA in the serum samples showed no remarkable effect(s) on the sensitivity and specificity of the sensing tool. Since the differences of absorption values was used in the calculations, the effect of background absorption (at $525 \mathrm{~nm}$ ) in the serum samples was removed in the assays.

For the reversibility of engineered immunosensors, we utilized glycine- $\mathrm{HCl}\left(0.15 \mathrm{~mol} \mathrm{~L}^{-1}, \mathrm{pH} 2.0\right)$ in two regeneration cycles for

Table 1

Comparison of the immunosensor with published biosensors for detection of PSA.

\begin{tabular}{|c|c|c|c|c|}
\hline Biosensor materials & Technique & $\operatorname{LDR}\left(\mathrm{ng} \mathrm{mL}^{-1}\right)$ & $\mathrm{LOD}\left(\mathrm{pg} \mathrm{mL} \mathrm{L}^{-1}\right)$ & Ref. \\
\hline $\mathrm{Fe}_{3} \mathrm{O}_{4}-\mathrm{TMB}-\mathrm{H}_{2} \mathrm{O}_{2}$ & Photothermometry & $1-64$ & 1000 & [37] \\
\hline DNA-AuNPs & Colorimetry & & 0.182 & [38] \\
\hline PA-Cu-MOG & Fluorescence & $0.5-8$ & 330 & [39] \\
\hline GCE-GO@AuNRs-GOD-SA-biotin-DNA & ECL & $0.0005-5$ & 0.17 & {$[40]$} \\
\hline $\mathrm{Ab}_{1}-(\mathrm{PSA})-\mathrm{Ab}_{2}-\mathrm{AuNPS}-\mathrm{Cu}$ & Colorimetry & & 3.4 & [41] \\
\hline PGE-PANI-AuNPs-PNT-Ab ${ }_{1}-\mathrm{Ab}_{2}$-HRP & Electrochemistry & $1-100$ & 680 & [17] \\
\hline Ab-Au-Bi2Se3 nanosheets & Colorimetry & $1-10,000$ & 72 & [42] \\
\hline AuE-DNA-AgNPs-Apt & Electrochemistry & $0.001-160$ & 0.11 & [43] \\
\hline AuNPs-ATCUN-Peptide- $\mathrm{Fe}_{3} \mathrm{O}_{4}$ & Colorimetry & $0-0.8$ & 20 & [44] \\
\hline \multirow[t]{2}{*}{$A b_{1}-(P S A)-A b_{2}-H R P-P p y N P s$} & Colorimetry & & 0.7 & [45] \\
\hline & Electrochemistry & & 0.8 & \\
\hline GCE-AuNPs-Ni(OH) $)_{2}-\mathrm{NGQDs}-\mathrm{Ab}_{1}-(\mathrm{PSA})-\mathrm{Ab}_{2}-\mathrm{Fe}_{3} \mathrm{O}_{4} @ \mathrm{MnO}_{2}$ & ECL & $0.00001-10$ & 0.000005 & {$[46]$} \\
\hline AuE-GRP-PS $67-$ b-PAA 27 & Electrochemistry & $0.0001-100$ & 0.04 & [47] \\
\hline GCE-Au@Pt NCs-Ab & Electrochemistry & $0.1-50$ & 18 & [48] \\
\hline Peptide- $\mathrm{Fe}_{3} \mathrm{O}_{4} @ \mathrm{SiO}_{2}-\mathrm{Au}$ & Fluorescence & $0.001-1$ & 0.3 & [49] \\
\hline AuE-MSTF-Apt & Electrochemistry & $1-300$ & 280 & [50] \\
\hline $\mathrm{Fe}_{3} \mathrm{O}_{4}-\mathrm{Ab}_{2-}(\mathrm{PSA})-\mathrm{Ab}_{1}-\mathrm{AuNPs}$ & Colorimetry & $0.01-20$ & 9 & This work \\
\hline
\end{tabular}

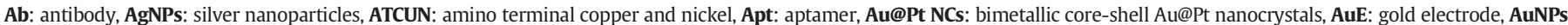

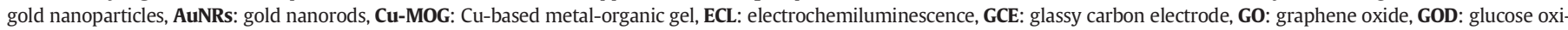

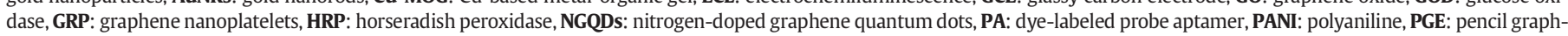
ite electrode, PNT: peptide nanotube composite, PpyNPs: Polypyrrole nanoparticles, $\mathbf{P S}_{\mathbf{6 7}}$-b-PAA $\mathbf{2 7}$ : diblock co-polymer, $\mathbf{S A}$ : streptavidin, TMB: (3,3',5,5'-tetramethylbenzidine). 
Table 2

Real sample analyses and comparison of the immunosensor with a standard ELISA assay.

\begin{tabular}{|c|c|c|c|c|c|}
\hline Patient type & No. & ELISA [PSA] $\left(\mathrm{ng} \mathrm{mL}^{-1}\right)$ & Added [PSA] $\left(\mathrm{ng} \mathrm{mL}^{-1}\right)$ & Found $[\mathrm{PSA}]\left(\mathrm{ng} \mathrm{mL} \mathrm{L}^{-1}\right)$ & Recovery (\%) \\
\hline \multirow[t]{3}{*}{ Healthy individuals } & 1 & $1.4 \pm 0.3$ & 0 & $1.37 \pm 0.23$ & $97.86 \pm 0.77$ \\
\hline & 1 & $1.4 \pm 0.3$ & 5 & $6.34 \pm 0.41$ & $99.06 \pm 1.37$ \\
\hline & 1 & $1.4 \pm 0.3$ & 10 & $11.53 \pm 0.34$ & $101.14 \pm 1.13$ \\
\hline \multirow[t]{3}{*}{ Prostate cancer patients } & 2 & $6.2 \pm 0.2$ & 0 & $6.33 \pm 0.16$ & $102.10 \pm 0.80$ \\
\hline & 2 & $6.2 \pm 0.2$ & 5 & $11.41 \pm 0.32$ & $101.88 \pm 1.60$ \\
\hline & 2 & $6.2 \pm 0.2$ & 10 & $15.89 \pm 0.25$ & $98.09 \pm 1.25$ \\
\hline
\end{tabular}

$3 \mathrm{~min}$. The immunosensor displayed reversibility efficiency of $95.1 \% \pm$ 1.2 (for five replication) up to 5 cycles with an acceptable reproducibility and precision. In our study, the engineered immunosensors were regenerated in the fixed concentration of PSA (i.e., $10 \mathrm{ng} \mathrm{mL} \mathrm{m}^{-1}$ ). Additionally, the engineered $A b_{1}-A u N P s$ and $\mathrm{Fe}_{3} \mathrm{O}_{4}-\mathrm{Ab}_{2}$ were found to be extremely stable at room temperature during 45 and 30 days postfabrication with coefficient variation percentage (CV\%) $<5.4 \%$ and $5.2 \%$ respectively. The reagents of immunoassay were found to be stable up to 90 days at refrigerator temperature $\left(4^{\circ} \mathrm{C}\right)$ and after this period of time, dramatic decrease was observed in the performance of immunosensor.

\section{Conclusions}

In summary, we have demonstrated the feasibility of a colorimetric immunoassay for determination of PSA using SPR band of colloidal AuNPs. In this work, antibody-conjugated AuNPs were exposed to the PSA antigen molecules in the presence of second antibody-conjugated $\mathrm{Fe}_{3} \mathrm{O}_{4}$ to form a network of an immune complex. Residual $\mathrm{Ab}_{1}$-AuNPs (unreacted NPs) were utilized for measurement of SPR signals. This sandwich-type method is simple and rapid, and other signalproducing NPs can be engineered in the platform of this sensing system. However, the sensing approach allows the detection of PSA within the $0.01-20 \mathrm{ng} \mathrm{mL}^{-1}$ range of PSA concentrations in real samples. In general, similar to any other sensing platform in which antibody is involved, our assay is faced with the limitation of incubation time (130 min) for completion of antigen-antibody complexation reaction. This incubation time can limit instant analysis of PSA protein. In conclusion, we envisioned that the simple but reliable and efficient platform of this immunosensor to be useful in the development of future point-of-care sensing tools, working on the quantification of biomarkers in a drop of blood.

\section{Author contributions}

The manuscript was written through the contributions of all authors. All authors have given approval to the final version of the manuscript.

\section{Acknowledgment}

The authors would like to thank National Institute for Medical Research Development (NIMAD) for the financial support this work (Grant No. 957699).

\section{Appendix A. Supplementary data}

Supplementary data to this article can be found online at https://doi. $\operatorname{org} / 10.1016 /$ j.saa.2019.117218.

\section{References}

[1] M.J. Barry, Prostate-specific-antigen testing for early diagnosis of prostate cancer, N. Engl. J. Med. 344 (2001) 1373-1377, https://doi.org/10.1056/NEJM200105033441806.

[2] F. Bray, J. Ferlay, I. Soerjomataram, R.L. Siegel, L.A. Torre, A. Jemal, Global cancer statistics 2018: GLOBOCAN estimates of incidence and mortality worldwide for 36 cancers in 185 countries, CA Cancer J. Clin. 68 (2018) 394-424, https://doi.org/10.3322/ caac. 21492.
[3] H.C.B. Graves, M. Kamarei, T.A. Stamey, Identity of prostate specific antigen and the semen protein p30 purified by a rapid chromatography technique, J. Urol. 144 (1990) 1510-1515, https://doi.org/10.1016/S0022-5347(17)39788-4.

[4] J.J. Hlavaty, A.W. Partin, F. Kusinitz, M.J. Shue, A. Stieg, K. Bennett, J.V. Briggman, Mass spectroscopy as a discovery tool for identifying serum markers for prostate cancer, Clin. Chem. 47 (2001) 1924 LP-1926http://clinchem.aaccjnls.org/content/ 47/10/1924.abstract.

[5] Y. Wang, A. Brunsen, U. Jonas, J. Dostálek, W. Knoll, Prostate specific antigen biosensor based on long range surface plasmon-enhanced fluorescence spectroscopy and dextran hydrogel binding matrix, Anal. Chem. 81 (2009) 9625-9632, https://doi. org/10.1021/ac901662e.

[6] E.E. Kline, E.G. Treat, T.A. Averna, M.S. Davis, A.Y. Smith, L.O. Sillerud, Citrate concentrations in human seminal fluid and expressed prostatic fluid determined via $1 \mathrm{H} \mathrm{nu}-$ clear magnetic resonance spectroscopy outperform prostate specific antigen in prostate cancer detection, J. Urol. 176 (2006) 2274-2279.

[7] G. Koukouvinos, A. Metheniti, C.E. Karachaliou, D. Goustouridis, E. Livaniou, K. Misiakos, I. Raptis, A. Kondili, P. Miniati, P. Petrou, S. Kakabakos, White light reflectance spectroscopy biosensing system for fast quantitative prostate specific antigen determination in forensic samples, Talanta 175 (2017) 443-450, https://doi.org/10. 1016/j.talanta.2017.07.074

[8] M.J. Donohue, M.B. Satterfield, J.J. Dalluge, M.J. Welch, J.E. Girard, D.M. Bunk, Capillary electrophoresis for the investigation of prostate-specific antigen heterogeneity, Anal. Biochem. 339 (2005) 318-327, https://doi.org/10.1016/j.ab.2005.01.043.

[9] Y. Zheng, H. Chen, X.-P. Liu, J.-H. Jiang, Y. Luo, G.-L. Shen, R.-Q. Yu, An ultrasensitive chemiluminescence immunosensor for PSA based on the enzyme encapsulated liposome, Talanta 77 (2008) 809-814.

[10] L.I. Stowell, L.E. Sharman, K. Hamel, An enzyme-linked immunosorbent assay (ELISA) for prostate-specific antigen, Forensic Sci. Int. 50 (1991) 125-138, https:// doi.org/10.1016/0379-0738(91)90141-5.

[11] F. Zhang, L. Mao, M. Zhu, Ultrasensitive immunoassay for free prostate-specific antigen based on ferrocenecarboxylate enhanced cathodic electrochemiluminescence of peroxydisulfate, Microchim. Acta 181 (2014) 1285-1291, https://doi.org/10.1007/ s00604-014-1240-7.

[12] S.M. Khoshfetrat, H. Khoshsafar, A. Afkhami, M.A. Mehrgardi, H. Bagheri, Enhanced visual wireless electrochemiluminescence immunosensing of prostate-specific antigen based on the luminol loaded into MIL-53 (Fe)-NH2 accelerator and hydrogen evolution reaction mediation. Anal. Chem. 91 (2019) 6383-6390.

[13] G. Sun, H. Liu, Y. Zhang, J. Yu, M. Yan, X. Song, W. He, Gold nanorods-paper electrode based enzyme-free electrochemical immunoassay for prostate specific antigen using porous zinc oxide spheres-silver nanoparticles nanocomposites as labels, New J. Chem. 39 (2015) 6062-6067, https://doi.org/10.1039/c5nj00629e.

[14] T. Soukka, J. Paukkunen, H. Härmä, S. Lönnberg, H. Lindroos, T. Lövgren, Supersensitive time-resolved immunofluorometric assay of free prostate-specific antigen with nanoparticle label technology, Clin. Chem. 47 (2001) 1269-1278.

[15] T. Kaya, T. Kaneko, S. Kojima, Y. Nakamura, Y. Ide, K. Ishida, Y. Suda, K. Yamashita, High-sensitivity immunoassay with surface plasmon field-enhanced fluorescence spectroscopy using a plastic sensor chip: application to quantitative analysis of total prostate-specific antigen and GalNAcß1-4GlcNAc-linked prostate-specific antigen for prost, Anal. Chem. 87 (2015) 1797-1803, https://doi.org/10.1021/ ac503735e.

[16] Y. Seto, T. Iba, K. Abe, Development of ultra-high sensitivity bioluminescent enzyme immunoassay for prostate-specific antigen (PSA) using firefly luciferase, Luminescence 16 (2001) 285-290, https://doi.org/10.1002/bio.654.

[17] T. Vural, Y.T. Yaman, S. Ozturk, S. Abaci, E.B. Denkbas, Electrochemical immunoassay for detection of prostate specific antigen based on peptide nanotube-gold nanoparticle-polyaniline immobilized pencil graphite electrode, J. Colloid Interface Sci. 510 (2018) 318-326, https://doi.org/10.1016/j.jcis.2017.09.079.

[18] N. Chen, M. Rong, X. Shao, H. Zhang, S. Liu, B. Dong, W. Xue, T. Wang, T. Li, J. Pan, Surface-enhanced Raman spectroscopy of serum accurately detects prostate cancer in patients with prostate-specific antigen levels of $4-10 \mathrm{ng} / \mathrm{mL}$, Int. J. Nanomedicine Volume 12 (2017) 5399-5407, https://doi.org/10.2147/JJN.S137756.

[19] J.H. Lee, K.S. Hwang, J. Park, K.H. Yoon, D.S. Yoon, T.S. Kim, Immunoassay of prostatespecific antigen (PSA) using resonant frequency shift of piezoelectric nanomechanical microcantilever, Biosens. Bioelectron. 20 (2005) 2157-2162, https://doi.org/10. 1016/j.bios.2004.09.024.

[20] V.K. Gupta, A.K. Singh, L.K. Kumawat, Thiazole Schiff base turn-on fluorescent chemosensor for Al3 ion, Sensors Actuators B Chem. 195 (2014) 98-108, https:// doi.org/10.1016/j.snb.2013.12.092.

[21] V.K. Gupta, N. Mergu, L.K. Kumawat, A.K. Singh, Selective naked-eye detection of Magnesium (II) ions using a coumarin-derived fluorescent probe, Sensors Actuators B Chem. 207 (2015) 216-223, https://doi.org/10.1016/j.snb.2014.10.044. 
[22] V.K. Gupta, N. Mergu, L.K. Kumawat, A.K. Singh, A reversible fluorescence "off-onoff" sensor for sequential detection of aluminum and acetate/fluoride ions, Talanta 144 (2015) 80-89, https://doi.org/10.1016/j.talanta.2015.05.053.

[23] M.L. Yola, V.K. Gupta, T. Eren, A.E. Sen, N. Atar, A novel electro analytical nanosensor based on graphene oxide/silver nanoparticles for simultaneous determination of quercetin and morin, Electrochim. Acta 120 (2014) 204-211, https://doi.org/10. 1016/j.electacta.2013.12.086.

[24] K.E. Sapsford, W.R. Algar, L. Berti, K.B. Gemmill, B.J. Casey, E. Oh, M.H. Stewart, I.L. Medintz, Functionalizing nanoparticles with biological molecules: developing chemistries that facilitate nanotechnology, Chem. Rev. 113 (2013) 1904-2074, https://doi.org/10.1021/cr300143v.

[25] H. Karimi-Maleh, F. Tahernejad-Javazmi, N. Atar, M.L. Yola, V.K. Gupta, A.A. Ensafi, A novel DNA biosensor based on a pencil graphite electrode modified with polypyrrole/functionalized multiwalled carbon nanotubes for determination of 6mercaptopurine anticancer drug, Ind. Eng. Chem. Res. 54 (2015) 3634-3639, https://doi.org/10.1021/ie504438z.

[26] V. Gupta, H. Karimi-maleh, R. Sadeghi, Simultaneous determination of hydroxylamine, phenol and sulfite in water and waste water samples using a voltammetric nanosensor, Int. J. Electrochem. Sci. 10 (2014) 303-316.

[27] A. Asfaram, M. Ghaedi, S. Agarwal, I. Tyagi, V.K. Gupta, Removal of basic dye Auramine-O by ZnS:Cu nanoparticles loaded on activated carbon: optimization of parameters using response surface methodology with central composite design, RSC Adv. 5 (2015) 18438-18450, https://doi.org/10.1039/c4ra15637d.

[28] V.K. Gupta, N. Atar, M.L. Yola, Z. Üstündağ, L. Uzun, A novel magnetic Fe@ Au coreshell nanoparticles anchored graphene oxide recyclable nanocatalyst for the reduction of nitrophenol compounds, Water Res. 48 (2014) 210-217.

[29] L.H. Reddy, J.L. Arias, J. Nicolas, P. Couvreur, Magnetic nanoparticles: design and characterization, toxicity and biocompatibility, pharmaceutical and biomedical applications, Chem. Rev. 112 (2012) 5818-5878, https://doi.org/10.1021/cr300068p.

[30] J. Sun, Y. Xianyu, X. Jiang, Point-of-care biochemical assays using gold nanoparticleimplemented microfluidics, Chem. Soc. Rev. 43 (2014) 6239-6253, https://doi.org/ 10.1039/C4CS00125G

[31] M.R. Hormozi-Nezhad, P. Karami, H. Robatjazi, A simple shape-controlled synthesis of gold nanoparticles using nonionic surfactants, RSC Adv. 3 (2013) 7726-7732.

[32] P. Hashemi, H. Bagheri, A. Afkhami, Y. Hosseinzadeh Ardakani, T. Madrakian, Fabrication of a Novel Aptasensor Based on Three-Dimensional Reduced Graphene Oxide/Polyaniline/Gold Nanoparticle Composite as a Novel Platform for High Sensitive and Specific Cocaine Detection, 996, 2017 10-19.

[33] J.M. Perez, Iron oxide nanoparticles: hidden talent, Nat. Nanotechnol. 2 (2007) 535.

[34] R. De Palma, S. Peeters, M.J. Van Bael, H. den Rul, K. Bonroy, W. Laureyn, J. Mullens, G. Borghs, G. Maes, Silane ligand exchange to make hydrophobic superparamagnetic nanoparticles water-dispersible, Chem. Mater. 19 (2007) 1821-1831, https://doi. org/10.1021/cm0628000.

[35] T. Sannomiya, C. Hafner, J. Vörös, Shape-dependent sensitivity of single plasmonic nanoparticles for biosensing, J. Biomed. Opt. 14 (2009) 064027, https://doi.org/10. $1117 / 1.3269678$.

[36] S. Ahmed, S. Ikram, Synthesis of gold nanoparticles using plant extract: an overview, iMedPub, n.d. http://nanotechnology.imedpub.com/synthesis-of-gold-nanoparticles-using-plant-extract-an-overview.php?aid=7649 (accessed May 10, 2019).

[37] G. Fu, S.T. Sanjay, W. Zhou, R.A. Brekken, R.A. Kirken, X. Li, Exploration of nanoparticle-mediated photothermal effect of TMB-H2O2 colorimetric system and its application in a visual quantitative photothermal immunoassay, Anal. Chem. 90 (2018) 5930-5937, https://doi.org/10.1021/acs.analchem.8b00842.
[38] X. Kou, T. Liu, X. Yang, Y. Tang, X. Gong, P. Miao, Role of Tripodal DNA modified gold nanoparticles in colorimetric aptasensing, Colloid Interface Sci. Commun. 21 (2017) 19-21, https://doi.org/10.1016/j.colcom.2017.11.001.

[39] T.T. Zhao, Z.W. Peng, D. Yuan, S.J. Zhen, C.Z. Huang, Y.F. Li, Metal-organic gel enhanced fluorescence anisotropy for sensitive detection of prostate specific antigen, Spectrochim. Acta A Mol. Biomol. Spectrosc. 192 (2018) 328-332, https://doi.org/ 10.1016/j.saa.2017.10.072.

[40] J.-T. Cao, J.-J. Yang, L.-Z. Zhao, Y.-L. Wang, H. Wang, Y.-M. Liu, S.-H. Ma, Graphene oxide@ gold nanorods-based multiple-assisted electrochemiluminescence signal amplification strategy for sensitive detection of prostate specific antigen, Biosens. Bioelectron. 99 (2018) 92-98.

[41] Y. Liu, Z. Zhang, J. Yu, J. Xie, C.M. Li, A concentration-dependent multicolor conversion strategy for ultrasensitive colorimetric immunoassay with the naked eye, Anal. Chim. Acta 963 (2017) 129-135, https://doi.org/10.1016/j.aca.2017.01.034.

[42] L. Xiao, A. Zhu, Q. Xu, Y. Chen, J. Xu, J. Weng, Colorimetric biosensor for detection of cancer biomarker by au nanoparticle-decorated Bi2Se3 nanosheets, ACS Appl. Mater. Interfaces 9 (2017) 6931-6940, https://doi.org/10.1021/acsami.6b15750.

[43] P. Miao, Y. Jiang, Y. Wang, J. Yin, Y. Tang, An electrochemical approach capable of prostate specific antigen assay in human serum based on exonuclease-aided target recycling amplification, Sensors Actuators B Chem. 257 (2018) 1021-1026, https:// doi.org/10.1016/j.snb.2017.11.064.

[44] N. Xia, D. Deng Y. Wang C. Fang S.-J. Li, Gold nanoparticle-based colorimetric method for the detection of prostate-specific antigen, Int. J. Nanomedicine 13 (2018) 2521-2530, https://doi.org/10.2147/IJN.S154046.

[45] W. Hong, S. Lee, Y. Cho, Dual-responsive immunosensor that combines colorimetric recognition and electrochemical response for ultrasensitive detection of cancer biomarkers, Biosens. Bioelectron. 86 (2016) 920-926, https://doi.org/10.1016/j.bios. 2016.07.014.

[46] W. Zhu, M.S. Khan, W. Cao, X. Sun, H. Ma, Y. Zhang, Q Wei, Ni(OH)2/NGQDs-based electrochemiluminescence immunosensor for prostate specific antigen detection by coupling resonance energy transfer with Fe304@MnO2 composites, Biosens. Bioelectron. 99 (2018) 346-352, https://doi.org/10.1016/j.bios.2017.08.005.

[47] M.S. Khan, K. Dighe, Z. Wang, I. Srivastava, E. Daza, A.S. Schwartz-Dual, J. Ghannam, S.K. Misra, D. Pan, Detection of prostate specific antigen (PSA) in human saliva using an ultra-sensitive nanocomposite of graphene nanoplatelets with diblock-: Co -polymers and Au electrodes, Analyst 143 (2018) 1094-1103, https://doi.org/10. 1039/c7an01932g.

[48] R. Wang, A.J. Wang, W.D. Liu, P.X. Yuan, Y. Xue, X. Luo, J.J. Feng, A novel label-free electrochemical immunosensor for ultra-sensitively detecting prostate specific antigen based on the enhanced catalytic currents of oxygen reduction catalyzed by core-shell Au@Pt nanocrystals, Biosens. Bioelectron. 102 (2018) 276-281, https:// doi.org/10.1016/j.bios.2017.11.041.

[49] L. Yang, N. Li, K. Wang, X. Hai, J. Liu, F. Dang A novel peptide/Fe304@SiO2-Au nanocomposite-based fluorescence biosensor for the highly selective and sensitive detection of prostate-specific antigen, Talanta 179 (2018) 531-537, https://doi. org/10.1016/j.talanta.2017.11.033.

[50] W. Argoubi, A. Sánchez, C. Parrado, N. Raouafi, R. Villalonga, Label-free electrochemical aptasensing platform based on mesoporous silica thin film for the detection of prostate specific antigen, Sensors Actuators B Chem. 255 (2018) 309-315, https:// doi.org/10.1016/j.snb.2017.08.045. 